\title{
THE KINETICS OF THE REDUCTION OF PROTONS AT POLYCRYSTALLINE AND MONOCRYSTALLINE GOLD ELECTRODES
}

\author{
G.J. BRUG, M. SLUYTERS-REHBACF: and J.H. SLUYTERS * \\ Van 't Hoff Laboratory of Physical and Collon.t Chemistry, Padualaan 8, 3584 CH Utrecht (The Netherlands)
}

A. HAMELIN

Laboratoire d'Electrochimie Interfaciale du C.N.R.S., I Place A. Briand, 92190 Meudon (France)

(Received 3rd May 1983; in final form 10th July 1984)

\begin{abstract}
The reduction of $\mathrm{H}^{+}$from $1 \mathrm{M} \mathrm{r}: \mathrm{CiO}_{4}$ and $1 \mathrm{M} \mathrm{NaClO}_{4}$ solutions at polycrystalline and single crystal faces of very pure gold electroders is studied by determining the forward rate constant $k_{f}$ as a function of potential and of $\mathrm{H}^{+}$concentration. The techniques applied are dc current and impedance measurements both with a step-wise variation of dc potential (duration $4 \mathrm{~s}$ ), and dc current measurements with a continuous potential variation. The consistency of the results is extensively tested and found to be quite satisfactory. Plots of $\ln k_{\mathrm{r}}$ vs. potential are curved and exhibit limiting slopes corresponding to values for the operational transfer coefficient $\alpha=1$ at positive and $\alpha=0.5$ at negative potentials. This behaviour is discussed in terms of mechanistic models described in the literature and also an alternative mechanism is tentatively proposed. An increase in the rate constants is observed wher the purity of the gold is iess. The slight differences in the rate constants observed. at single crystal faces of the same purity but with different crystallographic orientation are discussed.
\end{abstract}

\section{(I) INTRODUCTION}

The study of electrochemical kinetics at solid electrodes has often suffered from the poor quality of experimental results. As compared to the use of the dropping mercury electrode as a working electrode, the problems arising with solid electrcdes became painfully clear and practically all of the meaningful data and theories on electrode kinetics were obtained and tested at the dropping mercury electrode.

This is even more true in double-layer studies and it is only recently that surface preparation techniques have been developed that allow precise and reproducible results to be obtained in this field [1-3]. However, just a reproducibie state is sill unsatisfactory if this state is not known down to the atomic level and if this state depends too strongly on the kind of preparation procedure. If the latter arises the

* To whom correspondence should be addressed.

0022-0728/84/\$03.00 O 1984 Elsevier Sequoia S.A. 
experiments are being made on an electrode in a well-defined though arbitrary state. The effect of various pretreatments on the cyclic voltammogram of a platinum electrode in $1 \mathrm{M} \mathrm{H}_{2} \mathrm{SO}_{4}$ has been demonstrated by Breiter [4], and further pioneering work on the best way to remove trace impurities from the surface was don $z$ by Gilman [5]. From these and many other works the conclusion is justified that : inodic polarizazion just before the actual measurement brings about the desired remival of (adsorbed) impurities. The above-mentioned preparation procedures of goli! electrodes $[2,3]$ involve such a positive voltage perturbation, viz a siow sweepin $y$ to a well-chosen positive potential and back to the potential ct interest. During this sweep the gold is superficially oxidized and then subsequently reduced.

The reasons for the excellent quality of the dropping mercury electrode are twofold: (a) the surface is smooth and clean and (b) mass transport by diffusion and convection is well-defined if the measurcinents are taken at a fixed time, say 4 :; after drop birth. At solid electrodes it appenrs that the first property can be me: $t$ to a reasonable extent by the preparation procedures now available [1-3] and the second by choosing a voltage-time relation starting from outside the faradaic region, thus allowing the diffusion problem to be equally well defined. This can conveniently be combined with the anodic pretreatment, e.g. in a way as shown in Fig. 1. Th: mass transport in this case will be described by the theory of the well-known poiential step method. If the potential is recurrenily controlled following Fig. 1, then it gold electrode is made to function in a way that has a close similarity to a dripping mercury electrode or a static mercury drop electrode, with comparable insen:itivity to impurities in the solution.

A messuring technique most suitable for studies of electrode kinetics is undoubtedly the ac impedance method, because it is quite sensitive for mechinnstic details of a particular system and moreover theoretically accessible for complic ations involved therein. For example, adsorption of reactants or intermediates, whi: $h$ can be expected to occur more often at a solid electrode than at a mercury eler:trod :., can

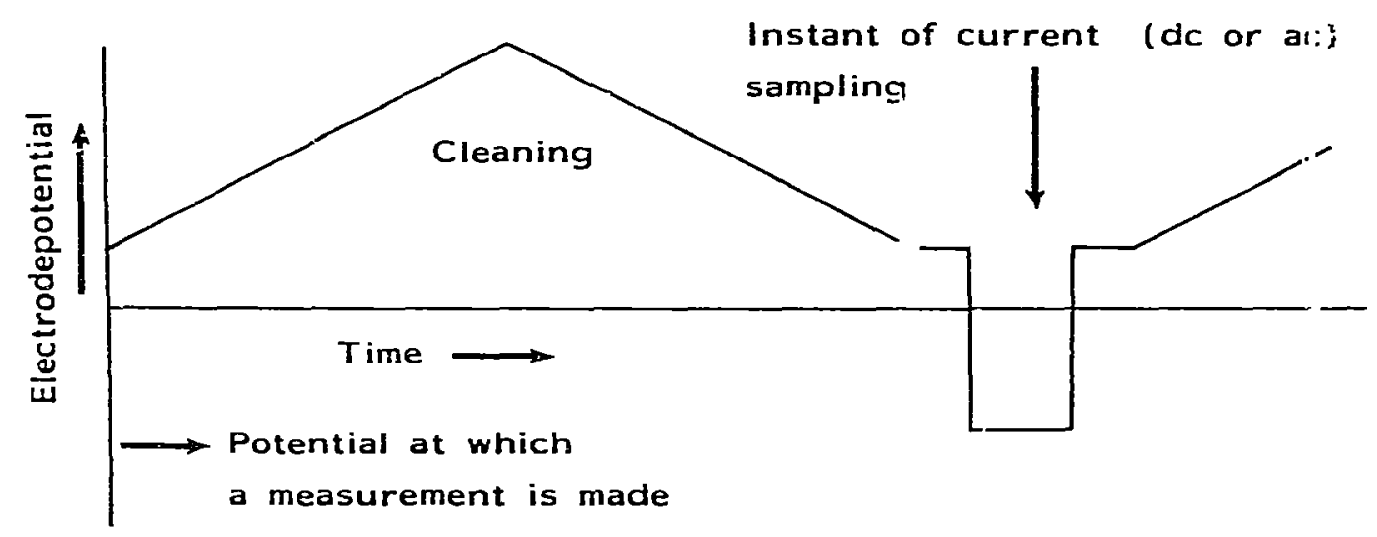

Fig. 1. Potential-time diagram of the programmed voltage perturbation. 
be recognized unambiguously from the frequency spectrum of the interfacial admiltance [6]. In addition, verification of the above stated expectations is most rigorously performed by inspecting the consistency of dc and ac results.

In this paper we report the results of a dc and ac study, applying the procedures advocated above to the reduction of $\mathrm{H}^{+}$ions at gold electrodes, both with polycrystalline and monocrystalline surfaces of different crystallographic orientations. This electrode reaction has been the subject of many previous studies. From a literature survey given by Kuhn and Byrne [7] and later articles of Sasaki and Mat:uda [8] the impression is obtained that the kinetic parameters (the exchange current density and the transfer coefficient) depend strongly on the chemical state of the electrode surface, to such an extent that there is hardly any agreement between the results of different investigations. On the other hand, the proton reduction has betn of theoretical interest for a long time as there is a number of classical treatrnents concerning the reaction mechanism as well as the dependence of the reaction sate on the nature of the electrode metal [9-13].

A question of particular interest is whether the kinctics of the $\mathrm{H}^{+}$reduction are, or should be, specifically dependent on the crystallographic orientation of a monocrystalline electrode [13-15]. Except for one publication [16], to our knowledge the effect of crystallographic orientation of gold electrodes has never been reported. We chose, therefore, to study the five faces of the face centered cubic system which should, according to the variation of the calculated surface free energy as a function of crystallographic orientation [17], show extreme behaviour, namely (111), (100), (110), (210) and (311). They were found to show extreme behaviour of the electrical double-layer as well [3].

Summarizing, the experiments to be described in this papi- will be focussed on three topics: (i) reliability and consistency of data and interpretatics (ii) mechanistic considerations and (iii) (specific) effects of crystallographic orientaitin on mechanism and/or kinetic parameters.

\section{(II) EXPERIMENTAL}

\section{(II.I) The solution}

The solutions were prepared from twice distilled water and J.T. Baker Ultrex reagents. Sodium perchlorate solutions were prepared by adding perchloric acid to sodium carbonate in equivalent amounts. The cell solutions were either $1 M$ perchloric acid solutions or mixtures of perchloric acid and sodium perchlorate of 1 $M$ total concentration.

The perchlorate anion was chosen because of its low tendency to adsorb specifically on the gold/water interface [18].

Oxygen was removed by purging with argon. The temperature of the cell solution was $25^{\circ} \mathrm{C}$, unless stated otherwis:. 


\section{(II.2) The electrodes}

The single crystals were prepared from gold bars (Johnson-Matthey, $5 \mathrm{~N}$ ) similarly to the Bridgeman method [2]. The crystals were grown from the melt in a graphite crucible, oriented with the aid of $X$-rays and cut along the desired crystallographic orientation.

The single crystal electrodes were mechanically polished with alumina of different grades down to $0.25 \mu \mathrm{m}$ and the disturbed layer at the surface was eliminated by electrolytic dissolution and annealing [2].

The polycrystalline electrodes were mechanically polished with diamond paste (or with alumina) of different grades down to $0.25 \mu \mathrm{m}$.

Before each experiment the electrode was annealed in a highly oxygenated flame of methane gas and cooled by dipping into fresh twice distilled water. This was in order to avoid contact of the electrode with air [19]. In the cell the surface of the electrode was contacted with the surface of the solution following the dipping technique (pendant meniscus method) described by Dickertmann et al. [1]. All the calculations have been performed on the basis of the apparent geometric surface areas, which could be determined with an accuracy of $\pm 5 \%$.

The counter electrode was a gold sheet of $6 \mathrm{~cm}^{2}$ (Johnson-Matthey, $5 \mathrm{~N}$ ). All potentials were measured versus a saturated sodium chloride calomel electrode (SSCE). The counter electrode and the glassware were cleaned with aqua regia, thoroughly rinsed with twice distilled water and steamed.

\section{(II.3) The measuring techniques}

First the working electrodes were subjected to cyclic linear potential sweeps between -0.25 and ca. $+1.40 \mathrm{~V}$ vs. SSCE with a sweep rate of $20 \mathrm{mV} \mathrm{s}^{-1}$ in order to obtain an indication of the purity and the physical state of the metal surface. This was done with $1 \mathrm{M} \mathrm{HClO}_{4}$ as the cell solution. During each sweep the gold is superficially oxidized and subsequen:ly reduced. The peaks in these cyclic voltammograms are characteristic for the structure of the interface. The application of these sweeps was continuously repeated until the cyclic voltammogram, by these characteristic peaks and its stationary behaviour, proved the interface to be in a reproducible state. At the start of each run of kinetic experiments the same procedure was applied, also as a check on the absence of impurities in the solution, or at the interface.

This slow change of the imposed potential for the anodic pretreatment was preferred to the fast potentiodynamic multipulse sequences employed by Gilman [5]. We feel that in our treatment irreversible changes of the outermost layer of atoms of the gold surface will be avoided and thus a possible effect of a changed physicai state of the surface is eliminated or at least reduced.

For the dc measurements concerning the $\mathrm{H}^{+}$redustion two ways of varying the potential were applied:

(a) Potential sweeps into the faradaic region. The current flowing was recorded. The 
value of this current was found to be independent of sweep ratt: between 20 and 5 $\mathrm{mV} \mathrm{s}^{-1}$ which indicates that the current-voltage relation obtained is kinetically controlled.

(b) Potential steps from an initial potential of $+0.400 \mathrm{~V}$ vs. SSCE, outside the faradaic region to subsequently more negative potentials in the faradaic region. In each step the current was sampled at $4 \mathrm{~s}$ after the start of it. In between two steps the potential was swept from the initial potential to a potential where the surface is oxidized (mostly $+1.400 \mathrm{~V}$ vs. SSCE) and back in order to maintain a clean electrode. In this way quite reproducible current-voltage curves could be recorded.

All potential excursions were achieved with the aid of a digital to analog converter controlled by the HP 9830 calculator of the Network Analyser system described earlier [20].

For the ac measurements the same program of potential control as in the step method was applied. On this potential a sinusoidal ac voltage of $10 \mathrm{mV}$ peak-to-peak was superimposed. The ac current amplitude and the phase angle were sampled $4 \mathrm{~s}$ after the start of the pulse with the Network Analyzer. The measurements were performed at twelve frequencies ranging from $80 \mathrm{~Hz}$ to $10 \mathrm{kHz}$ and at 16 potentials.

Outside the faradaic region the double layer capacity was measured by the potential sweep method described by Clavilier [21] at a single frequency of $20 \mathrm{~Hz}$. The values obtained provided another check of the state of the interfaces. With a good electrode the double layer capacitance values were found to be independent of the way of potential variation i.e. sweep or step.

(III) THEORY FOR DATA ANALYSIS

(III.I) The rate equation and the formard rate constant

It is generally accepted that the reduction of solvated protons to molecular hydrogen proceeds via a step-wise mechanism involving the following reactions: the discharge reaction

$\mathrm{H}^{+}\left(\mathrm{H}_{2} \mathrm{O}\right)_{h}+e^{-} \rightleftarrows h \mathrm{H}_{2} \mathrm{O}+\mathrm{H}_{\mathrm{ad}}$

followed by either, or both, the ion + atom reaction

$\mathrm{H}^{+}\left(\mathrm{H}_{2} \mathrm{O}\right)_{h}+\mathrm{H}_{\mathrm{ad}}+e^{-} \rightleftarrows h \mathrm{H}_{2} \mathrm{O}+\mathrm{H}_{2}$

and the combination reaction

$2 \mathrm{H}_{\mathrm{ad}} \rightleftarrows \mathrm{H}_{2}$

So the intermediate is supposed to be adsorbed atomic hydrogen, which either reacts with a second proton or combines with another adsorbed hydrogen atom, to form molecular hydrogen at the surface. It is assumed that the hydrogen molecule desorbs very fast:

The implications of this mechanism, and especially of the strength of the adsorption of atomic hydrogen, for the current-voltage characteristic has bcen 
treated in the literature several times [9,11-13,22,23]. A general rate equation accounting for R1, R2 and R3 simultaneously at any degree of coverage, is severely complex. It is usual therefore to consider several limiting cases separately; as for example in refs. 9,12 and 13, assuming the symmetry factors of the three steps to be equal to 0.5 . In the case of an irreversible reduction such a rate equation is of the type

$$
-j_{F}=F k_{\mathrm{f}} c_{\mathrm{H}^{+}}^{\mathrm{H}^{+}} c_{\mathrm{H}_{2}}^{\nu_{H_{2}}}
$$

The potential dependence of $k_{\mathrm{f}}$ can be characterized by

$(R T / F) \mathrm{d}\left(\ln k_{\mathrm{f}}\right) / \mathrm{d} E=-\alpha$

The asymptotic values of the cathodic transfer coefficient $\alpha$ and the stoichiometric coefficients depend on the type or mechanism, cf. the tabulations given in refs. 9 and 23.

\section{(III.2) The dc current}

For dc experiments, eqn. (1) will hold for the dc current $\bar{j}_{F}$ and the dc surface concentrations $\bar{c}_{\mathrm{H}^{+}}$and $\bar{c}_{\mathrm{H}_{2}}$, the latter two being generally different from the bulk concentrations $c^{*}{ }_{\mathrm{H}^{*}}$ and $c^{*}{ }_{\mathrm{H}_{2}}$.

As we worked with solutions that were originally free from hydrogen, it is more convenient to eliminate $\bar{c}_{\mathrm{H}_{2}}$. $A$ S a good approximation this can be done by introducing a linear relationship beiv'seen $\bar{j}_{F}$ and $\bar{c}_{\mathrm{H}_{2}}$, following the diffusion layer model:

$-\bar{j}_{F}=2 \mathrm{Fa}_{\mathrm{H}_{2}} \bar{c}_{\mathrm{H}_{2}}$

with $a_{\mathrm{H}_{2}}=D_{\mathrm{H}_{2}} / \delta_{\mathrm{H}_{2}}$, i.e. the diffusion coefficient of dissolved $\mathrm{H}_{2}$ divided by the diffusion layer thickness. Equation (3) requires that no hydrogen gas evolves. If this relation is substituted in the dc version of eqn. (1) we obtain

$$
-j_{F}=F k_{\mathrm{r}}^{1 /\left(1-\nu_{\mathrm{H}_{2}}\right)}\left(2 a_{\mathrm{H}_{2}}\right)^{-\nu_{\mathrm{H}_{2}} /\left(1-\nu_{\left.\mathrm{H}_{2}\right)}\right.} \bar{c}_{\mathrm{H}^{+}}^{\nu_{+} /\left(1-\nu_{\mathrm{H}_{2}}\right)}
$$

If $\nu_{H_{2}} \neq 0$ this has consequences for the apparent reaction order in $\bar{c}_{\mathrm{H}^{*}}$ and the potential dependence of $\bar{j}_{F}$. For this reason we have tabulated in Table 1 the values of $\nu_{\mathrm{H}^{+}}, \nu_{\mathrm{H}_{2}}$ and $\alpha$ for the limiting cases that are usually considered, together with values of the quantities

$\nu_{\mathrm{H}^{+}}=\left(\partial \ln \left(-j_{F}\right) / \partial \bar{c}_{\mathrm{H}^{+}}\right)_{E}=\nu_{\mathrm{H}^{+}} /\left(1-\nu_{\mathrm{H}_{2}}\right)$

and

$\ddot{u}^{\prime}=(R T / F)\left(\partial \ln \left(-j_{F}\right) / \partial E\right)_{\bar{c}_{\mathrm{H}^{+}}}=\alpha /\left(1-\nu_{\mathrm{H}_{2}}\right)$

The tabulated numbers have been deduced from general rate equations identical to those derived in ref. 13 . It may be noted that a partly similar compilation in a paper of Conway and Salomon [23] probably contains a printing error as regards case C.

At high $\mathrm{H}^{+}$concentrations the effect of mass transfer on $\bar{c}_{\mathrm{H}^{*}}$ will be negligible and it is allowable to replace $\bar{c}_{\mathrm{H}^{+}}$by ${ }^{*}{ }_{\mathrm{H}^{+}}$. Depending on the reaction mechanism 
and the extent of adsorption of the hydrogen atom, the reaction order in $\mathrm{c}^{*} \mathrm{H}^{+}$can be second, first or zero order, but also in between these values according to the $\nu_{\mathrm{H}^{*}}$ values in Table 1.

At low $\mathrm{H}^{+}$concentrations the diffusion of $\mathrm{H}^{+}$should be accounted for and even if we apply a diffusion layer model:

$$
-\bar{j}_{F}=\mathrm{Fa}_{\mathrm{H}^{+}}\left(c^{*} \mathrm{H}^{+}-\bar{c}_{\mathrm{H}^{+}}\right)
$$

with $a_{\mathrm{H}^{+}}=D_{\mathrm{H}^{+}} / \delta_{\mathrm{H}^{+}}$, this will lead to a complicated expression, unless the reaction order in $c_{\mathrm{H}^{*}}$ equals unity. If $\nu_{\mathrm{H}^{*}}=1$, the rigorous solution of the semi-infinite linear diffusion problem can be employed. In that case we have [24]

$-\bar{j}_{F}=F c^{*}{ }_{\mathrm{H}^{+}} \lambda \exp \left(\lambda^{2} t\right) \operatorname{erf} c\left(\lambda t^{1 / 2}\right)$

with

$\lambda=\left[k_{\mathrm{f}}(E)\right]^{1 /\left(1-\nu_{\left.\mathrm{H}_{2}\right)}\right.}\left(2 a_{\mathrm{H}_{2}}\right)^{-\nu_{\mathrm{H}_{2}} /\left(1-\nu_{\left.\mathrm{H}_{2}\right)}\right)} D_{\mathrm{H}^{! / 2}}^{-1 / 2}$

Note that eqn. (7) reduces to the "normal" expression $\lambda=k_{\mathrm{r}}(E) D_{\mathrm{H}}^{-1 / 2}$ if $\nu_{\mathrm{H}_{2}}=0$, and that we have $\nu_{\mathrm{H}_{2}} \neq 0$ only in the perhaps less probable cases $A \mathrm{~B}, \mathrm{AC}, \mathrm{Bb}$ and $\mathrm{Bc}$, see Table 1.

The treatment above of the dc current rests upon the assumption that the electrolysis time is sufficiently long to establish the stationary state, i.e. that the rate of reaction $R 1$ equals the sum of the rates of $R 2$ and $R 3$.

\section{TABLE 1}

Stoichiometric coefficients and transfer coefficients for the relation $\bar{j}_{F}=f\left(E, \bar{c}_{\mathrm{H}^{+}}, \bar{c}_{\mathrm{H}_{2}}\right)$, cf eqn. (1), and for the relation $\bar{j}_{F}=\mathbb{I}\left(E, \bar{c}_{\mathrm{H}^{+}}\right)$after elimination of $\vec{c}_{\mathrm{H}_{2}}$ (see text). $\boldsymbol{\theta}_{\mathrm{H}}=$ fractional surface coverage of atomic hydrogen

\begin{tabular}{|c|c|c|c|c|c|c|}
\hline Miechanism & & $\nu_{\mathrm{H}^{+}}$ & $\nu_{\mathrm{H}_{2}}$ & $\alpha$ & $\nu_{H^{+}}$ & $\alpha^{\prime}$ \\
\hline $\begin{array}{l}\text { A. } \mathbf{R} 1+\mathbf{R} 2 \\
\mathbf{R} 1 \text { rate determining }\end{array}$ & $\begin{array}{l}\text { (a) } \theta_{H} \ll 0.5 \\
\text { (b) } \theta_{H}=0.5 \\
\text { (c) } \theta_{H} \gg 0.5\end{array}$ & $\begin{array}{l}1 \\
1.5 \\
2\end{array}$ & $\begin{array}{l}0 \\
-0.5 \\
-1\end{array}$ & $\begin{array}{l}0.5 \\
1 \\
1.5\end{array}$ & $\begin{array}{l}1 \\
1 \\
1\end{array}$ & $\begin{array}{l}0.5 \\
0.67 \\
0.75\end{array}$ \\
\hline $\begin{array}{l}\text { B. } R 1+R 3 \\
\text { R1 rate determining }\end{array}$ & $\begin{array}{l}\text { (a) } \theta_{H} \ll 0.5 \\
\text { (b) } \theta_{H} \approx 0.5 \\
\text { (c) } \theta_{H} \gg 0.5\end{array}$ & $\begin{array}{l}1 \\
1 \\
1\end{array}$ & $\begin{array}{l}\mathbf{0} \\
-0.25 \\
-0.5\end{array}$ & $\begin{array}{l}0.5 \\
0.5 \\
0.5\end{array}$ & $\begin{array}{l}1 \\
0.8 \\
0.67\end{array}$ & $\begin{array}{l}0.5 \\
0.4 \\
0.33\end{array}$ \\
\hline $\begin{array}{l}\text { C. } R 1+R 2 \\
R 2 \text { rate determining }\end{array}$ & $\begin{array}{l}\text { (a) } \theta_{H}=0.5 \\
\text { (b) } \theta_{H}=0.5 \\
\text { (c) } \theta_{H}>0.5\end{array}$ & $\begin{array}{l}2 \\
1.5 \\
1\end{array}$ & $\begin{array}{l}0 \\
0 \\
0\end{array}$ & $\begin{array}{l}1.5 \\
1 \\
0.5\end{array}$ & $\begin{array}{l}2 \\
1.5 \\
1\end{array}$ & $\begin{array}{l}1.5 \\
1 \\
0.5\end{array}$ \\
\hline $\begin{array}{l}\text { D. } R 1+R 3 \\
R 3 \text { rate determining }\end{array}$ & $\begin{array}{l}\text { (a) } \theta_{H} \ll 0.5 \\
\text { (b) } \theta_{H}=0.5 \\
\text { (c) } \theta_{H} \gg 0.5\end{array}$ & $\begin{array}{l}2 \\
1 \\
0\end{array}$ & $\begin{array}{l}0 \\
0 \\
0\end{array}$ & $\begin{array}{l}2 \\
1 \\
0\end{array}$ & $\begin{array}{l}2 \\
1 \\
0\end{array}$ & $\begin{array}{l}2 \\
1 \\
0\end{array}$ \\
\hline
\end{tabular}


(III.3) The charge transfer resistance and the interfacial admittance

If the stationary state is assumed to hold also on the ac time scale, the charge transfer resistance, $R_{\mathrm{cl}}$, defined as

$R_{\mathrm{ct}}^{-1}=\left(\partial j_{F} / \partial E\right)_{c_{11}+c_{\mathrm{H}_{2}}}$

is easily derived from eqn. (1) and (2). It follows that

$R_{\mathrm{cl}}^{-1}=\left[\mathrm{d}\left(\ln k_{\mathrm{r}}\right) / \mathrm{d} E\right] \bar{j}_{F}=-(F / R T) \alpha \bar{j}_{F}$

Because of the irreversible character of the $\mathrm{H}^{+}$reduction the absence of a mass transport impedance can safely be assumed, so that $R_{\mathrm{cl}}^{-1}$ will be the only element parallel to the double layer admittance. In a separate study [25] we have paid attention to the fact that at solid electrodes the latter should not bi: represented by a pure capacitance, but rather by the so-called "constant phast element" (CPE). It was shown that reliable $R_{\mathrm{ct}}$ values can be obtained using an extrapolation procedure followed by an internal check.

Since the ac time scale of impedance measurements-using frequencies up to several $\mathrm{kHz}$ - is much shorter than the dc time scale, non-stationary proceeding of the reaction sequence is not unlikely to be observed in the interfacial admittance. In that case the faradaic admittance $Y_{F}$ becomes more complex, as has been shown by Gerischer and Mehi [10]. Following their derivation the frequency dependence of $Y_{F}$ is expressed by $[6,10]$

$Y_{F}=R_{\infty}^{-1}-\frac{a b}{b^{2}+\omega^{2} C_{\mathrm{H}}^{2}}+i \frac{\omega C_{\mathrm{H}} a}{b^{2}+\omega^{2} C_{\mathrm{H}}^{2}}$

where $R_{\infty}, a$ and $b$ are functions of $\bar{c}_{\mathrm{H}^{+}}$, the fractional surface coverage $\theta_{\mathrm{H}}$ and $E$; $C_{\mathrm{H}}=F \Gamma_{\mathrm{m}}$ ( $\Gamma_{\mathrm{m}}$ is maximum coverage) is called the "adsorption capacity". It can be shown that

$R_{\mathrm{cl}}^{-1}=R_{\infty}^{-1}-(a / b)$

Evidently this is the low frequency limit of the real part of eqn. (i0). Note, however, that a possible non-stationa:y behaviour can be reflected by the imaginary part, which reduces at low frequen $y$ y to $i \omega C_{\mathrm{H}}$, i.e. to an "adsorption capacitance" parallel to the double layer admittani:e.

At sufficiently high freque icies the second term in eqn. (10) will become infinitely small, so that apparently a "charge transfer resistance" $R_{\infty}$ remains. The meaning of this parameter is, of course, lifferent from that of $R_{\mathrm{ct}}$ and most probably its value will not be consistent with ecin. (9).

We may conclude that a combined analysis of ac and de results can be useful for drawing conclusions about the mechanism of the overall $\mathrm{H}^{+}$reduction. 

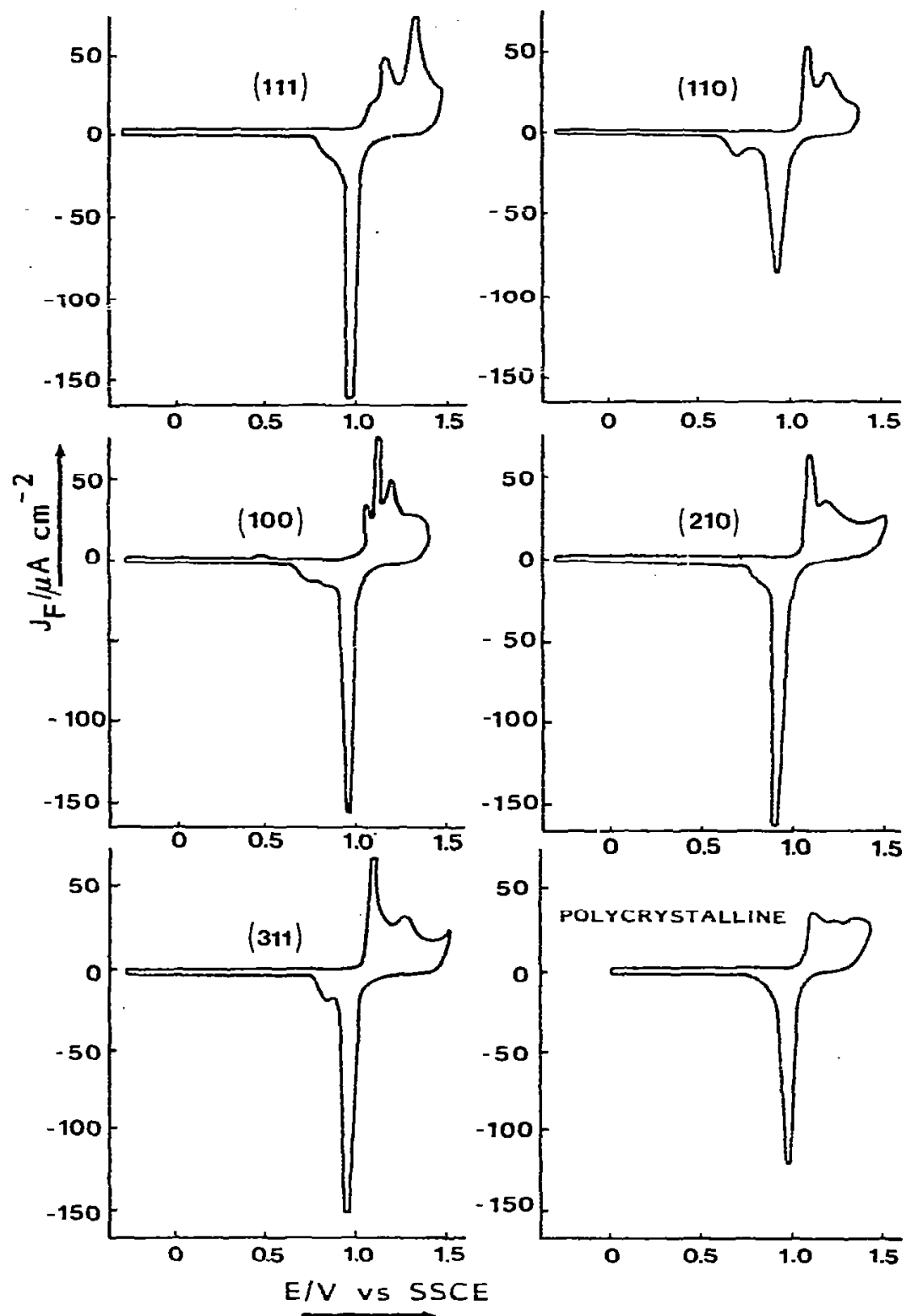

Fig. 2. Cyclic voltammograms for the five gold single crystal faces and polycrystalline gold in $1 M$ perchloric acid, sweep rate $20 \mathrm{mV} \mathrm{s}^{-1}$. 
(IV) RESULTS AND DISCUSSION

\section{(IV.I) Characterization of the electrodes}

\section{(IV.I.I) Cyclic voltammograms}

The cyclic voltammograms recorded in $1 \mathrm{M} \mathrm{HClO}_{4}$ solution before each series of experiments are reproduced in Fig. 2. The applied potential region includes the double-layer region $(-0.250$ to ca. $+0.6 \mathrm{~V}$ vs. SSCE) as well as the region of oxide formation $(+0.6 \mathrm{~V}$ to $+1.4 \mathrm{~V}$ vs. SSCE). The latter shows a fine structure that is significantly specific for the crystal orientation.

Some controversy exists in the literature about the question as to whether such fine structures are essentially related to different stages of oxide formation, or are rather due to trivial causes such as low surface roughness or edge effects. Discussions on this problem can be found, for example, in the works of Sotto [26] and of Dickertmann et al. [27]. For our purpose it was sufficient to use the cyclic voltammograms as a monitor for surface reproducibility, as we found the kinetics of $\mathrm{H}^{+}$-reduction to be quite reproducible if the patterns in Fig. 2 were established. The potentials of the peaks observed are listed in Table 2. If, instead of argon, hydrogen was purged into the solution, no oxidation or adsorption of hydrogen was observed between -0.50 and $+1.40 \mathrm{~V}$ vs. SSCE. In the cyclic voltammograms no signs of changes were observed during the experiments indicating that repeated cycling under our conditions does not affect the roughness of the electrode nor the structure of the top layer of atoms at the surface.

TABLE 2

Potentials of peaks in the cyclic voltammogram of single crystal faces of gold in $1 M$ perchloric acid. Sweep rate $20 \mathrm{mV} \mathrm{s}^{-1}$; temperature $19 \pm 2^{\circ} \mathrm{C}$

\begin{tabular}{lll}
\hline $\begin{array}{l}\text { Crystallographic } \\
\text { orientation }\end{array}$ & $\begin{array}{l}\text { Potentials of oxidation peaks } \\
E / \mathrm{V} \text { vs. SSCE }\end{array}$ & $\begin{array}{l}\text { Potentials of reduction peaks } \\
E / \mathrm{V} \text { vs. SSCE }\end{array}$ \\
\hline (111) & 1.07 (shoulder) & 0.94 \\
& 1.13 & 0.82 (shoulder) \\
& 1.29 & \\
$(110)$ & 1.09 & 0.95 \\
& 1.21 & 0.70 \\
$(100)$ & 0.48 (minor peak) & 0.96 \\
& 1.06 & 0.82 (shoulder) \\
& 1.10 & 0.73 (shoulder) \\
& 1.18 & \\
$(210)$ & 1.32 & 0.95 \\
& 1.07 & 0.81 (shoulder) \\
$(311)$ & 1.18 & 0.95 \\
& 1.095 & 0.845 \\
& 1.28 & 0.78 (shoulder) \\
\hline
\end{tabular}




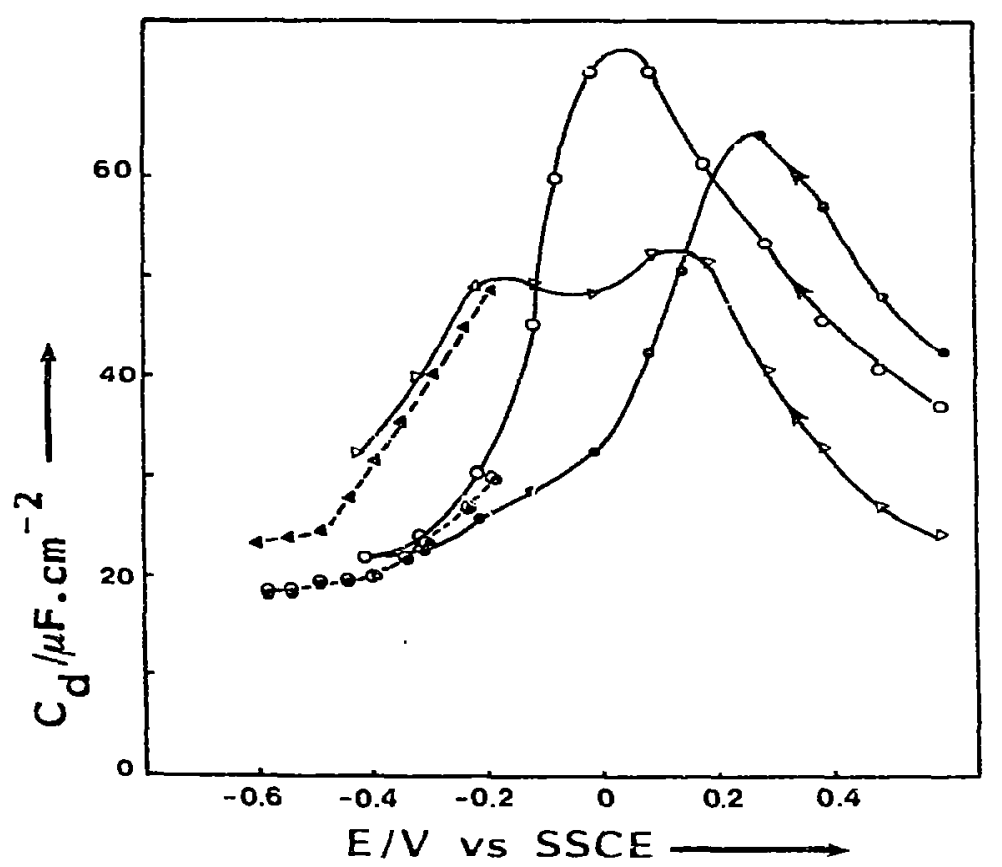

Fig. 3. Capacitance-potential curves for three faces of gold in $1 / M$ perchloric acid obtained: by potential sweep (-), by potential step $(-\ldots),,(\theta)(1 i 1),(\Delta)(110)$ and $(O)(100)$.

\section{(IV.1.2) Double-layer capacitance}

In the non-faradaic region, i.e. at approximately $-0.40<E<+0.60 \mathrm{~V}$ vs. SSCE, the double layer capacitance $C_{\mathrm{d}}$ of three single crystal electrodes ((111), (110) and (100)) was measured at a single frequency, $20 \mathrm{~Hz}$, by the potential sweep method described by Clavilier [21]. Within the faradaic region of $\mathrm{H}^{+}$reduction the values of $C_{\mathrm{d}}$ were obtained from the frequency spectrum analysis, as has been described elsewhere [25]. The results, represented in Fig. 3, reveal that the two sets connect reasonably' well at each of the three single crystal electrodes. The capacitance in the faradaic region appears to have reached the well-known minimum (ca. $20 \mu \mathrm{F} \mathrm{cm}{ }^{-2}$ ) without any evidence of an adsorption capacitance being present.

(IV.2) $\mathrm{H}^{+}$reduction at a polycrystalline electrode; concentration denendence

In a first series of experiments dc step voltammograms were mieasured at the polycrystalline electrode in contact with $1 \mathrm{M} \mathrm{NaClO}_{4}$ solution containing $\mathrm{HClO}_{4}$ at concentrations ranging from $4.75 \times 10^{-3}$ to $34 \times 10^{-3} M$. The limiting current density $j_{F, l}$ was found to be proportional to $c^{*} \mathrm{H}^{+}$. Usirs, the Cotirell equation, the diffusion coefficient was calculated: $D_{\mathrm{H}^{+}}=77.4 \times 10^{-1} \mathrm{~cm}^{2} \mathrm{~s}^{-1}$, in very good agreement with the value $76.0 \times 10^{-6}$ obtained from a dc polarogram at the dropping mercury electrode. The step voltammograms were normalized by plotting $j_{F} / j_{F, 1}$ vs. $E$ in Fig. 4 . The coincidence of the data is satisfactory and gives evidence that eqn. (6) is applicable. Using this equation and assuming $\nu_{\mathrm{H}_{2}}=0$ the values of 


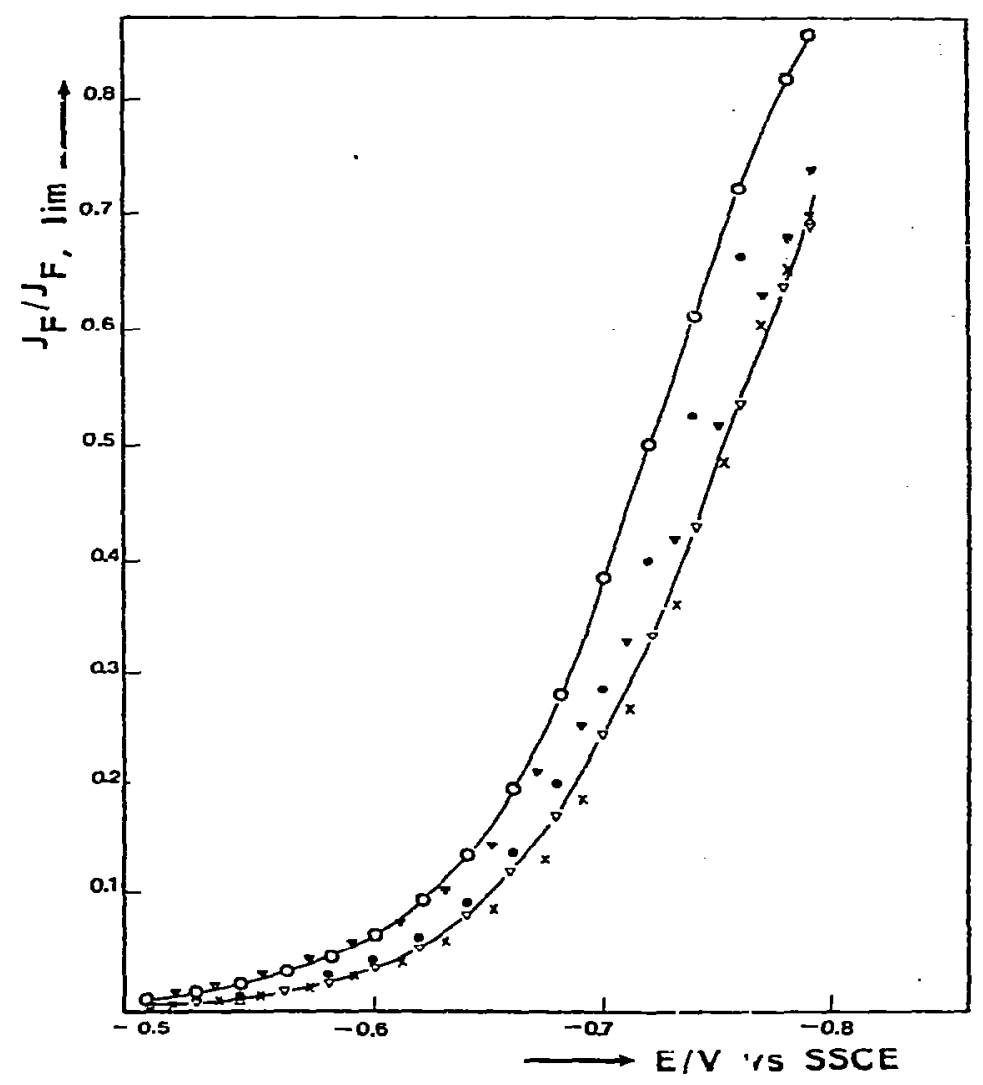

Fig. 4. Normalized potential step voltammograms a. a polycrystalline goid electrode for different concentrations of solvated protons: $(\nabla) 4.75 \times 10^{-3}$ (O) $9.5 \times 10^{-3},(\bullet) 10.5 \times 10^{-3},(\times) 18.6 \times 10^{-3},(\nabla)$ $34 \times 10^{-3} \mathrm{~mol}^{-1}$.

In $k_{\mathrm{r}}$ were calculated, which are plotted against potential in Fig. 5, together with a part of the In $k_{\mathrm{f}}$ vs. $E$ plot obtained at the polycrystalline electrode in $1 \mathrm{M} \mathrm{HClO}_{4}$.

Although there are some non-systematic discrepancies between the different runs, each run (except the one at $34 \mathrm{~m} M \mathrm{H}^{+}$) clearly produces an almost straight $\ln k_{\mathrm{r}}$ vs. $E$ plot, with a slope corresponding to a transfer coefficient ranging from $\alpha=0.50 \pm$ 0.02 in the most negative potential region to $\alpha=0.60 \pm 0.02$ at more positive potentials. The mutual difference between the $\ln k_{\mathrm{f}}$ values at fixed potential in Fig. 5 is $\mathbf{0 . 5}$ or less. This gives a good indication of the overall reproducibility of essentially different runs. Moreover, the rate constants determined for the $1 \mathrm{M} \mathrm{HClO}_{4}$ solution connect very well to the results at low $\mathrm{H}^{+}$concentration. Especially the latter fact proves that in the potential range considered the reaction is first order in $c_{\mathrm{H}^{+}}$. 


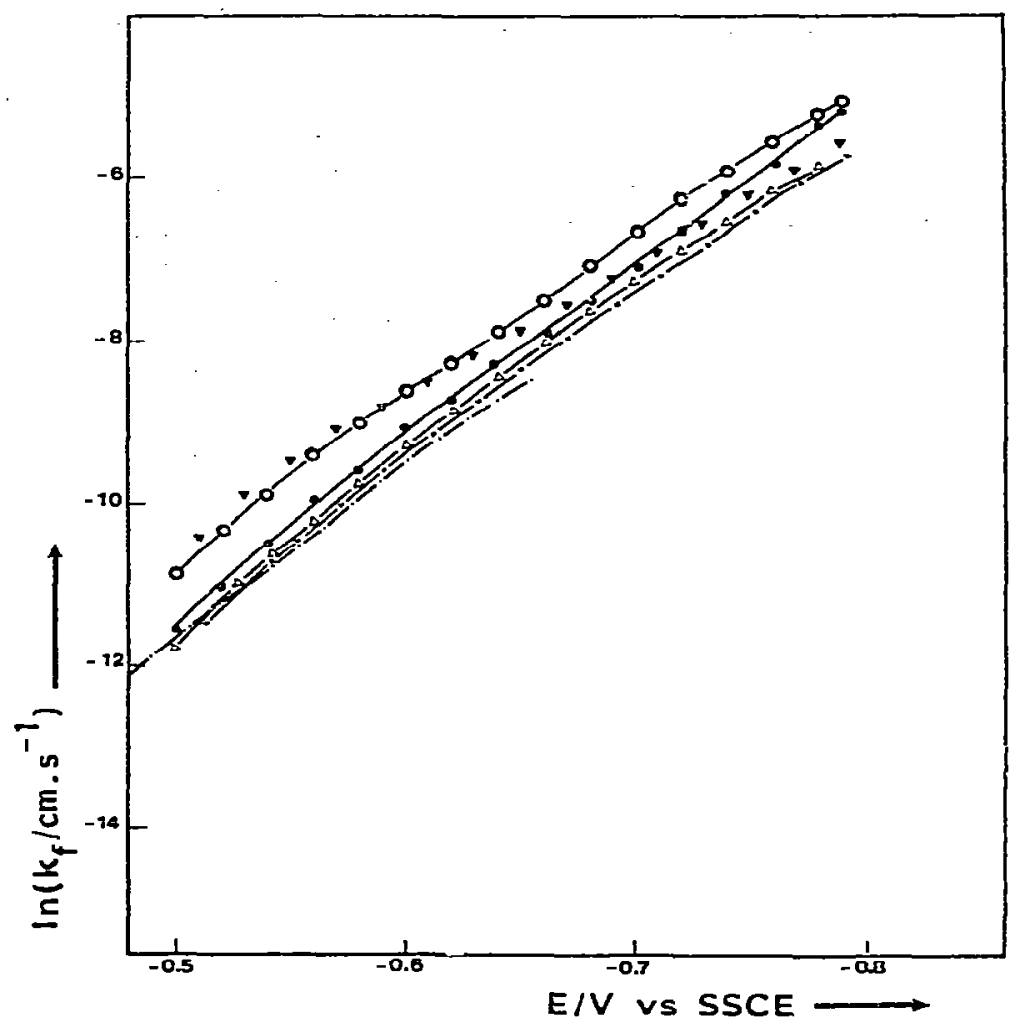

Fig. 5. The forward rate constant vs. potential derived from the data in Fig. 3. $(\Delta) 4.75 \times 10^{-3},(O)$ $9.5 \times 10^{-3}$, () $10.5 \times 10^{-3},(\times) 18.6 \times 10^{-3},(\Delta) 34 \times 10^{-3}$ and (-.--) $1.00 \mathrm{~mol} \mathrm{1}^{-1} . E^{\circ}=-0.235^{\circ} \mathrm{V}$ vs. SSCE.

As in the next section the potential depenclence of the reaction is studied in a more positive potential region (between $-0.2<$. and $-0.6 \mathrm{~V}$ vs. SSCE), a separate experiment was performed to determine the reaction order in $c_{\mathrm{H}^{-}}$at potentials as high as possible. Since then the current densities are extremely low, a working electrode with a large surface area (ca. $10 \mathrm{~cm}^{2}$, also $5 \mathrm{~N}$ quality) was used to measure dc step voltammograms of a solution containing $1 M \mathrm{HCIO}_{4}$ and a solution containing $0.1 \mathrm{M} \mathrm{HClO}_{4}+0.9 \mathrm{M} \mathrm{NaClO}_{4}$. The currents obtained yield a fairly straight Tafel plot in the region -0.23 to $-0.34 \mathrm{~V}$ vs. SSCE for $1 \mathrm{M} \mathrm{H}^{+}$and in the region -0.28 to $-0.38 \mathrm{~V}$ for $0.1 \mathrm{M} \mathrm{H}^{+}$. The slopes of these Tafel plots correspond to $\alpha=0.93 \pm 0.02$ in both cases. The reaction order in $c_{\mathrm{H}}$. calculated as $\Delta \log j_{F} / \Delta$ $\log c_{\mathrm{H}^{+}}$, varied from 0.96 at $F=-0.28 \mathrm{~V}$ to 0.71 at $E=-0.38 \mathrm{~V}$ vs. SSCE.

In may be noted that this behaviour is observed at potentials quite close to the standard potential of the $\mathrm{H}^{+} / \mathrm{H}_{2}$ reaction, which equils $-0.235 \mathrm{~V}$ vs. SSCE. 
(IV.3) $\mathrm{H}^{+}$reduction from $1 \mathrm{M} \mathrm{HClO}_{4}$ at mono- and polycrystalline electrodes

\section{(IV.3.1) Potential dependence}

The impedance measurements were analyzed using the procedure developed in a separite paper [25] to obtain the value of the charge transfer resistance $R_{\mathrm{ct}}$ as a function of dc potential. In Fig. 6 plots are made of (a) $\ln \left(R_{c l}^{-1} / c^{*} H^{+}\right)+\ln \left(R T / F^{2}\right)$, derived from the impedance measurements and (b) $\ln \left(j_{F} / F_{C}{ }^{*}{ }_{H^{+}}\right)$, derived from the dc ste $\rightarrow$ voltammograms, both measured at the polycrystalline electrode and at three different single crystal electrodes in contact with a $1 \mathrm{M} \mathrm{HClO}_{4}$ solution. Because of

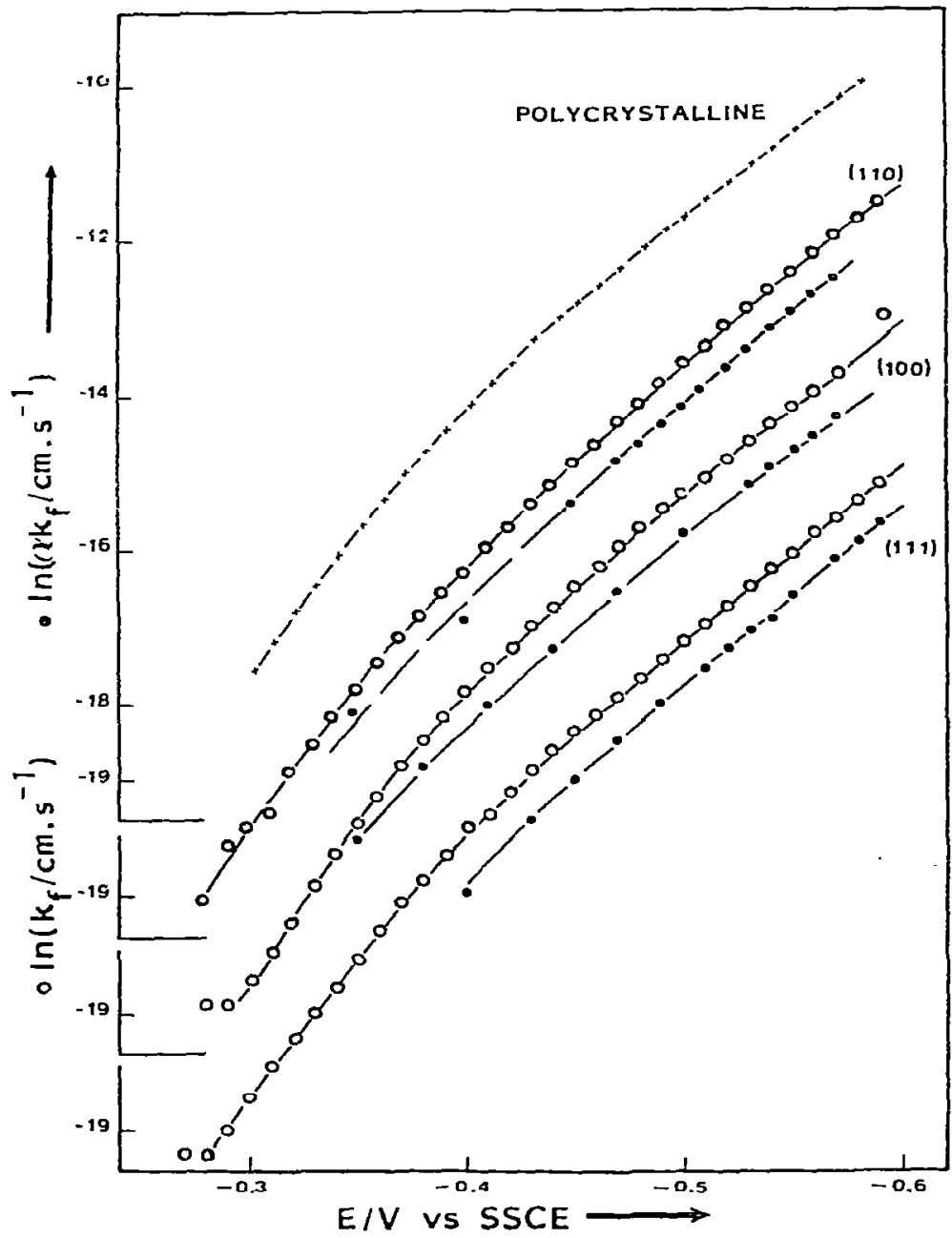

Fig. 6. $\ln \left(k_{1}\right)$ and $\ln \left(\alpha k_{\mathrm{f}}\right)$ vs. potential obtained for single crystal faces of gold (100), (110) and (111) and polycrystalline gold (only $\ln k_{\mathrm{f}}$ ) in $1 M$ perchloric acid from potential step (O) ind impedance measurements $(\theta)$ respectively. 
the high $\mathrm{H}^{+}$concentration diffusion control will be negligible in the potential region investigated and so, if $\nu_{\mathrm{H}_{2}}=0$ and $\nu_{\mathrm{H}^{+}}=1$ curve (b) should represent $\ln k_{\mathrm{f}}$ directly, whereas curve (a) will represent $\ln \left(\alpha k_{\mathrm{f}}\right)$. It appears tha: the experimental data are fairly consistent with these premises corresponding to a value of $\alpha=0.55$ to 0.6 at poteritials between -0.60 and $-0.45 \mathrm{~V}$ vs. SSCE, and to increasing $\alpha$ values at more positive potentials. A similar combined analysis of impedance and dc step data at a low $\mathrm{H}^{+}$concentration $(6.4 \mathrm{mM})$ in $1 \mathrm{M} \mathrm{NaClO}_{4}$ exhibited the same consistency and confirmed the slight change of $\alpha$ with potential $(a=0.47$ to 0.65$)$ as mentioned above.

The reproducibility of these measurements in $1 \mathrm{M} \mathrm{HClO}_{4}$ was tested several times by repeating the runs. In both the current and the impedance measurements any discrepancy never exceeded $2 \%$. Since the potential programming described in the experimental section causes one run to last about $4 \mathrm{~h}$, it can be concluded that the reactivity of the electrode surface exposed to the solution remains stable. It can be inferred therefore that the electrode surface remains in the same chemical and physical state during its contact with the cell solution. The considerable effect of preanodization, as observed by Sasaki and Matsuda [8], is absent in our experiments. Combining our whole set of data (see also section IV.2), we find a gradual increase in $\alpha$ from the value 0.5 at $E=-0.75 \mathrm{~V}$ vs. SSCE up to unity at $E=-0.24 \mathrm{~V}$ vs. SSCE.

In addition to the step measurements also current-potential curves were recorded for five single crystal faces in $1 \mathrm{M} \mathrm{HClO}_{4}$ by the potential sweep method described at several scan rates. These measurements were performed at room temperature, $19 \pm 2^{\circ} \mathrm{C}$. The resulting voltammograms appeared to be independent of scan rate if the scan rate was less than $20 \mathrm{mV} \mathrm{s}^{-1}$. However, for the (100) face some dependence on scan rate remained down to $2.5 \mathrm{mV} \mathrm{s}^{-1}$. The values of the rate constant, calculated as $\ln k_{\mathrm{f}}=\ln \left(-j_{F} / F c_{\mathrm{H}^{+}}^{*}\right)$, and plotted against potential in Fig. $7 \mathrm{~B}$, are quite close to the data obtained from the step measurements (Fig. 7A). However, the slopes of the $\ln _{\mathrm{f}} k_{\mathrm{f}}$ vs. $E$ curves from the sweep experiments appear to be liss steep, especially at the lower current densities. This tendency was found to be st:-onger at higher sweep rates: e.g. $\alpha=0.53$ in the region -0.40 to $-0.50 \mathrm{~V}$ vs. SSCE, as compared with $\alpha=0.65$ obtained from the step experiments in this region.

In connection with this, it may be mentioned that both Kuhn and Byrne [7] and Sasaki and Matsuda [8] determined Tafel plots at a polycrystalline gold electrode of $4 \mathrm{~N}$ quality in $\mathrm{H}_{2} \mathrm{SO}_{4}$ solutions and found a much steeper Tafel slope at low current densities compared with our step experiments. Kuhn and Byrne mentioned that currents at the lowest polarization generally took 2 or 3 hours to become steady. On the other hand, Schmid [28] has studied a polycrystalline gold electrode in $1 M$ $\mathrm{HClO}_{4}$ applying a procedure involving intermediate anodic prepolarizations and obtained a curved in $k_{\mathrm{f}}$ vs. $E$ plot with slopes quite close to the slopes in our Fig. 7A. This could suggest a conclusion that the electrolysis time and the treatment of the electrode between two measurements have an effect on the curvature of the Tafel plots.

Proton reduction from perchloric acid on single crystalline (111), (100) and (110) 


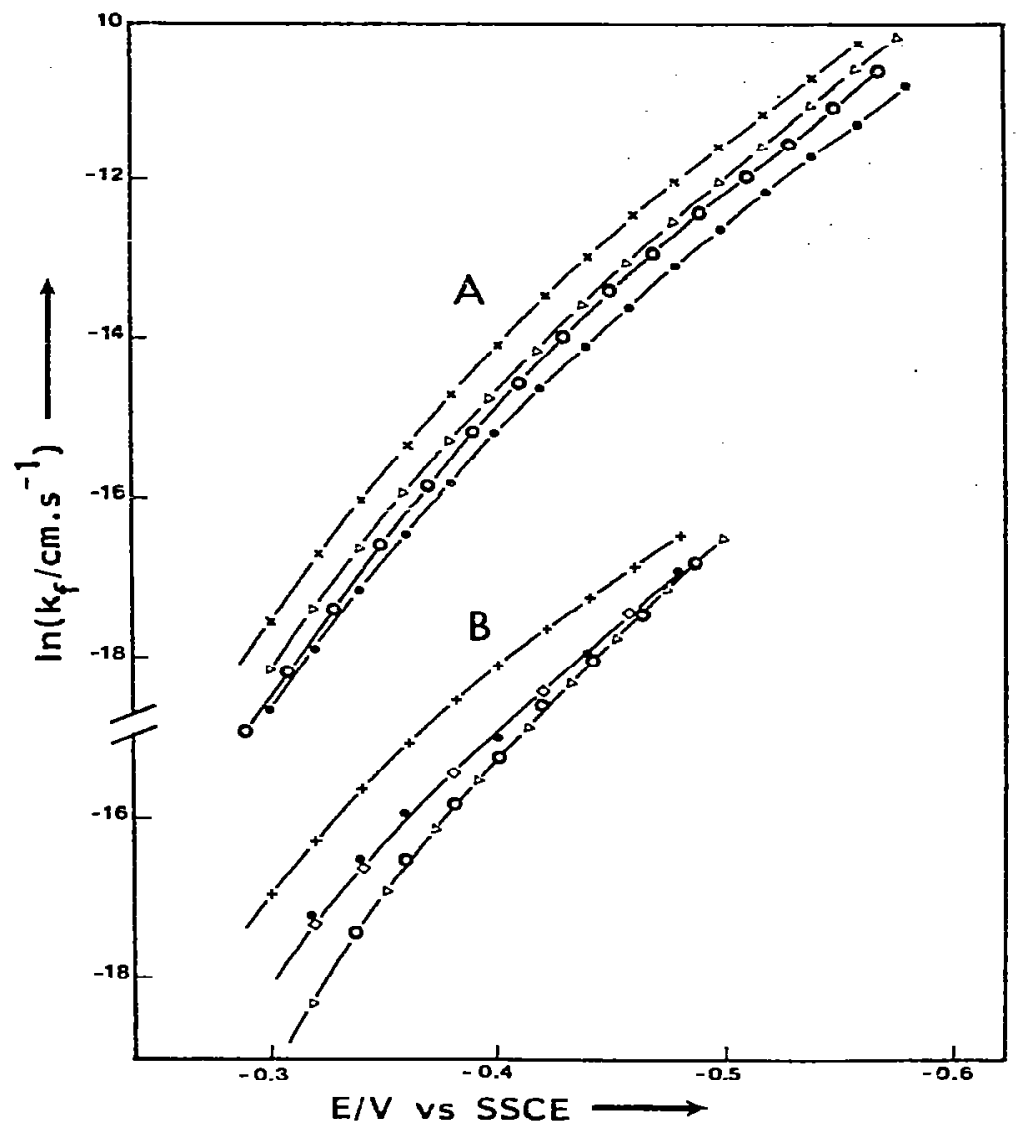

Fig. 7. $\ln \left(k_{\mathrm{f}}\right)$ vs. potential for $1 M$ perchloric acid. (A) potential step measurements, (B) potential sweep measurements. $(+)(311) 4 \mathrm{~N}$, (口) $(210) \equiv(311),(0)(100),(\bullet)(111)$ and $(\Delta)(110) ;(\times)$ polycrystalline electrode. $E^{\circ}=-0.235 \vee$ vs. SSCE.

faces of gold has been studied by Bicelli and Graziano [16]. They also observed curved Tafel plots, though with rather varying and irreproducible values for the slopes.

In one experiment, also reproduced in Fig. 7B, a (311) crystal face electrode made of gold $4 \mathrm{~N}$ (instead of gold $5 \mathrm{~N}$ used in all the other experiments) was used. The rate constants at this electrode are systematically higher by an amount of in $k_{\mathrm{f}}=\mathrm{ca}$. 1.0 , which is certainly more than the experimental errors in $k_{\mathrm{f}}$ due to the surface roughness (ca. 1 to $7 \%$ ) and the inaccuracy in the determination of the geometric area $( \pm 5 \%)$.

(IV.3.2) The mechanism of the proton reduction at gold

The curved plots in Fig. 7 can be very well described mathematically by an expression of the form 
$1 / k_{\mathrm{r}}=\exp (0.5 \phi) / L_{1}+\exp \left(\phi j / L_{2}\right.$

where $\phi=(F / R T)\left(E-E^{\circ}\right)$. Values of $L_{1}$ and $L_{2}$ (as yet empirical quantities), calculated taking $E^{\circ}=-0.235 \mathrm{~V}$ vs. SSCE, are listed in Table 3 . The fit to eqn. (12) is quite exclusive, i.e. attempts to replace $\exp (\phi)$ by e.g. $\exp (1.5 \phi)$, gave no satisfactory fit. As eqn. (12) is obeyed by our results down to $\phi=0$, it is easily realized that for any possible third term, e.g. $\exp (1.5 \phi) / L_{3}$ or $\exp (2 \phi) / L_{3}$, the value of $L_{3}$ should be larger than ca. 30 times $L_{2}$. It may be worth noting that the region of curvature in our Tafel plots is quite large (over $0.150 \mathrm{~V}$ ), in contrast to the sharp transition from one slope to another often reported in literature [29].

We conclude that the term in $\exp (0.5 \phi)$ represents the limiting behaviour of our results in the high overvoltage region (see also Fig. 5) and the term in $\exp (\dot{\phi})$ represents the limiting behaviour at potentials near $E^{\circ}$, hence we may try to deduce a plausible choice of mechanism regarding the cases of limiting behaviour collected in Table 1 . It is obvious that limiting behaviour with $\alpha=1$ at positive $E$ only occurs in mechanism $\mathrm{C}$ or $\mathrm{D}$ with $\theta_{\mathrm{H}}=0.5$. Then the limiting behaviour with $\alpha=0.5$ at negative $E$ can logically be explained by a change to either mechanism $C$ with

TABLE 3

Coefficients of the two exponential terms in eqn. (17) and the corresponding limiting values of the operationaj transfer coefficient

\begin{tabular}{|c|c|c|c|c|}
\hline & \multicolumn{2}{|l|}{ First term } & \multicolumn{2}{|l|}{ Second term } \\
\hline & $10^{8} L_{1} / \mathrm{cm} \mathrm{s}^{-1}$ & $\alpha_{\text {lim }}$ & $10^{9} L_{2} / \mathrm{cm} \mathrm{s}^{-1}$ & $\alpha_{\lim }$ \\
\hline \multicolumn{5}{|c|}{ A. Step measurements } \\
\hline polycryst. & 6.0 & 0.50 & 2.2 & 1.00 \\
\hline \multirow[t]{2}{*}{ (110) } & 4.2 & 0.50 & 1.0 & 1.02 \\
\hline & 3.4 & 0.52 & 1.1 & 1.02 \\
\hline (100) & 3.5 & 0.50 & 0.75 & 1.02 \\
\hline (111) & 1.8 & 0.52 & 0.8 & 1.00 \\
\hline \multicolumn{5}{|c|}{ B. Sw'eep measurements } \\
\hline$(110)$ & 3.0 & 0.49 & 0.4 & 1.05 \\
\hline$(100)$ & 3.0 & 0.49 & 0.4 & 1.05 \\
\hline (111) & 2.8 & 0.49 & 1.4 & 1.00 \\
\hline (210) & 2.8 & 0.49 & 1.2 & 1.00 \\
\hline (311) & 2.8 & 0.49 & 1.2 & 1.00 \\
\hline$(311)(4 N)$ & 3.5 & 0.50 & 5.0 & 1.02 \\
\hline \multicolumn{5}{|c|}{ C. Step measurements after Frumkin correction } \\
\hline \multirow[t]{2}{*}{$(110)$} & 1.2 & c.51 & 1.2 & 1.00 \\
\hline & 1.0 & 0.52 & 1.2 & 1.00 \\
\hline (100) & 0.65 & 0.51 & 0.9 & 1.00 \\
\hline (111) & 0.55 & 0.50 & 0.8 & 1.00 \\
\hline \multicolumn{5}{|c|}{ D. Sweep measurements after Frumkin correction } \\
\hline (110) & 0.75 & 0.50 & 0.6 & 1.00 \\
\hline (100) & 0.5 & 0.50 & 0.7 & 1.00 \\
\hline (111) & 0.7 & 0.50 & 2.0 & 1.00 \\
\hline
\end{tabular}


$\theta_{H} \gg 0.5$ or mechanism A with $\theta_{H} \ll 0.5$. (Mechanism B with $\theta_{H} \ll 0.5$ is excluded, because it would never lead to an increase of $\theta_{H}$ going to low current densities). We conclude that the mechanistic construction could be as follcws:

(a) In the more negative potential region the proton reduction proceeds by $\mathrm{R} 1$ followed by $R 2$, with either of them rate-determining.

(b) At less negative potentials the proton reduction involves fast proceeding of $R 1$, followed by either $\mathrm{F} 2$ or $\mathrm{R} 3$ as the rate-determining step. In view of the value found for $\nu_{H^{*}}^{\prime}$ (see sectio1: IV.2), R3 would be more probable than R2.

As argued befors:, this conclusion is based upon the assumption that stationary state behaviour exists, at least on the dc time scale (corresponding to electrolysis times of $4 \mathrm{~s}$ ). On the ac time scale it is sufficient to assume that the low frequency limit of eqn. (10) applies, so that the experimentally obtained charge transfer resistance obeys eqr. (11) and :hus eqn. (9), as is found in Fig. 6 . It is worth noting that the impedance data give no evidence of any adsorption capacitance, which, if it were present, would presumably be a function of potential. However, it is quite probable that its value is extremsly small in our case, since it is reported that the maximum coverage $\Gamma_{m}$ of hydrogen adsorption, and thus $C_{\mathrm{H}}$ in eqn. (10), should be extremely small, as would be expected from the absence of detectable hydrogen adsorption on the voltammograms.

It is difficuit to compare our reasonings with the rather inconsistent evidence present in the literature. In the review given by Kuhn and Byrne [7] it can be seen that usually only one Tafel slope is reported, but a variety of values between $0.12 \mathrm{~V}$ $(\alpha=0.5)$ to $0.03 \mathrm{~V}(\alpha=2)$ was found. Kuhn and Byrne themselves, in fact, proposed the same mechanist:c scheme as we suggested above on the basis of the observation of two Tafel slopes, $\alpha \approx 0.5$ and $\alpha \approx 2$, with a sharp transition in between. This must mean that in their case always $\theta_{\mathrm{H}} \ll 0.5$. However, the two exchange current densities that can be derived from their results are $i_{0}=40 \times 10^{-6} \mathrm{~A} \mathrm{~cm}^{-2}$ (hugh current densities where $\alpha=0.5$ ) and $i_{0}=3 \times 10^{-6} \mathrm{~A} \mathrm{~cm} \mathrm{~cm}^{-2}$ (low current densities where $\alpha=2$ ). These values are much higher than can be calculated from our data: $i_{0}=5.8 \times 10^{-6} \mathrm{~A} \mathrm{~cm}^{-2}$ (at high current densities where $\alpha=0.5$ ) and $i_{0}=0.21 \times 10^{-6}$ $A \mathrm{~cm}^{-2}$ (at low current densities where $\alpha=1$ ). The former value agrees well with the values selected in ref. 13 (Table 2.1.1) as "reliable" ones. It must be concluded therefore that Kuhn and Byme have worked with much more reactive gold surfaces. Moreover, a closer inspection of their results at three different concentrations $(0.01$, 0.1 and $1 \mathrm{M} \mathrm{H}_{2} \mathrm{SO}_{4}$ ) reveals that no single reaction order with respect to $c_{\mathrm{H}^{+}}$for $j_{F}$ at fixed $E-E^{\circ}$ can be defined and at low current densities it is certainly not equal to $\nu_{\mathrm{H}^{+}}=2$ as it should be.

It seems not striztly necessary to relate our experimental findings to the classical mechanistic scheme as given in Section (III.1) by the reaction R1, R2 and/or R3. An alternative scheme could be the following:

$$
\begin{aligned}
& \mathrm{H}^{+}\left(\mathrm{H}_{2} \mathrm{C}\right)_{h}+e^{-\underset{k_{-1}}{\stackrel{k_{1}}{\rightleftarrows}} h \mathrm{H}_{2} \mathrm{O}+\mathrm{H}_{\mathrm{ad}}} \\
& \mathrm{H}_{\mathrm{ad}}+\text { site } \rightarrow \mathrm{H}_{\text {site }}
\end{aligned}
$$


$\mathrm{H}_{\mathrm{ad}}+\mathrm{H}_{\text {site }} \rightarrow \mathrm{H}_{2}+$ site

The idea behind this scheme is to suppose the presence of "sites" (presumably foreign atoms) on the surface where $\mathrm{H}$-atoms are adsorbed more strongly than at the gold atoms is $-\mathrm{d}$ that the recombination reaction proceseds at these sites preferably. If reaction $R 2^{\prime}$ proceeds so fast that all sites are continuously occupied, the recombination process $\left(\mathrm{R}^{\prime}+\mathrm{R}^{\prime}\right)$ becomes pseudo-first order in $c_{\mathrm{H}}$ (the interfacial concentration of the intermediate $\mathrm{H}_{\mathrm{ad}}$ ), as we will have $v_{2}=v_{3}=k_{3}{ }^{\prime} c_{\mathrm{H}}$ - with $k_{3}^{\prime}$ being proportional to the densii; of sites. In the stationary state $v_{1}-v_{2}+v_{3}=2 v_{3}$, and consequently the overall forward rate constant will obey the expre:sion

$$
\frac{1}{k_{\mathrm{f}}}=\frac{1}{k_{1}}+\frac{K_{1}}{2 k_{3}^{\prime}}=\frac{\exp \left(\alpha_{1} \phi\right)}{k_{s_{1}}}+\frac{\exp (\phi)}{2 k_{3}^{\prime} \exp \left[(F / R T)\left(E^{\circ}{ }_{1}-E^{\circ}\right) \bar{j}\right.}
$$

where $k_{\mathrm{s}_{1}}=k_{1}\left(E=E^{\circ}\right)$ and $E^{\circ}{ }_{1}$ is the standard potential of the discharge reaction. The potential dependence of $k_{\mathrm{f}}$ in eqn. (13) is the same as that in the empirical eqn. (12) if $\alpha_{1}$ equals 0.5 . So, the scheme $R 1^{\prime}, R^{\prime}, R^{\prime}$ conforms to our experimental results. Although at present a definite proof is not possible, we think that this mechanism is quite probable in cases where the electrode surface has an extremely low density of sites.

In contrast with the classical schemes, the alternative involves both "stror.gly adsorbed" and "weakly adsorbed" hydrogen atoms, the latter produced at any point of the surface. This idea bears a resemblance to what is suggested to be the state of photo-electrochemically generated $\mathrm{H}$-atoms [30,31]. However, the results for the phctogenerated atomic hydrogen appear to depend on the crystallographic orientatior: of the surface of the gold electrode [32] so another mechanism might be operative in this case. On the other hand, our results could equally well be explained assuming the idea that the proton discharge, reaction $R 1$, is rate determining over the whole potential range of our measurements, but only changes from the "ordinary" behaviour to the behaviour corresponding to "barrierless discharge" [29,30,33-35]. At present it seems that a logical decision between various models is still harc to make. Probably a well planned study of the reaction at gold electrodes witi a deliberately modified number of adsorption sites is quite valuable for this purpose.

\section{(V.3) Effects of crystallographic orientation}

In a recent compilation of data on the proton reduction [13] it is concluded rinat exchange current densities are not significantly different at different crystal face; of either $\mathrm{V}, \mathrm{Ni}, \mathrm{Cu}, \mathrm{Mo}, \mathrm{W}$ or Pt.

In view of Fig. 7 and the data in Table 3, sections $A$ and $B$, the same conclusion seerns to apply for gold, although some plane-specificity is seen in the results of the potential step method. However, it is known that the potential of zero charge strongly depends on the crystallographic orientation and therefore a more proper comparison can be made after accounting for the influence of the double-layer structure, i.e. the Frumkin correction. For this purpose we estimated the potential, 
$\phi_{2}$, in the outer Helmholtz plane from the integrated double-layer capacities from Fig. 3, using the following values of the pzc: for the (110) plane $-0.06 \mathrm{~V}$ vs. SSCE, for the (100) plane $+0.10 \mathrm{~V}$ vs. SSCE, for the (111) plane $+0.20 \mathrm{~V}$ vs. SSCE. These values were obtained from the minima in the capacity-potential curves measured in $0.01 \mathrm{M} \mathrm{HClO}_{4}$ at our own electrodes and compare satisfactorily with values of the pzc obtained in $\mathrm{HClO}_{4}$ solutions for the (100) face [18] and the (111) face [36]. Absence of specific adsorption of $\mathrm{H}^{+}$and $\mathrm{ClO}_{4}^{-}$was assumed [18].

So-called Frumkin corrected plots were obtained from the results of the potential step measurements by plotting $\ln \left(k_{\mathrm{f}}\right)+(F / R T) \phi_{2}$ vs. $E-\phi_{2}$, leading to Fig. 8 . The conclusion is that the differences in the kinetics between the three crystal faces are of the same order of magnitude as in the non-corrected plots of Fig. 7. The conformity with eqn. (12) is maintained as follows from the data in Table 3, section C. Note that both the corrected $L_{1}$ value and the corrected $L_{2}$ value appear to depend (slightly) on the crystallographic orientation in the order $(111)<(100)<(110)$. However, a different trend is observed in the results from the potential sweep measurements given in Table 3 , section $D$.

At present it seems impossible to think of an entirely satisfactory interpretation of this result. It is well-known that the rate of proton reduction strongly depends on the

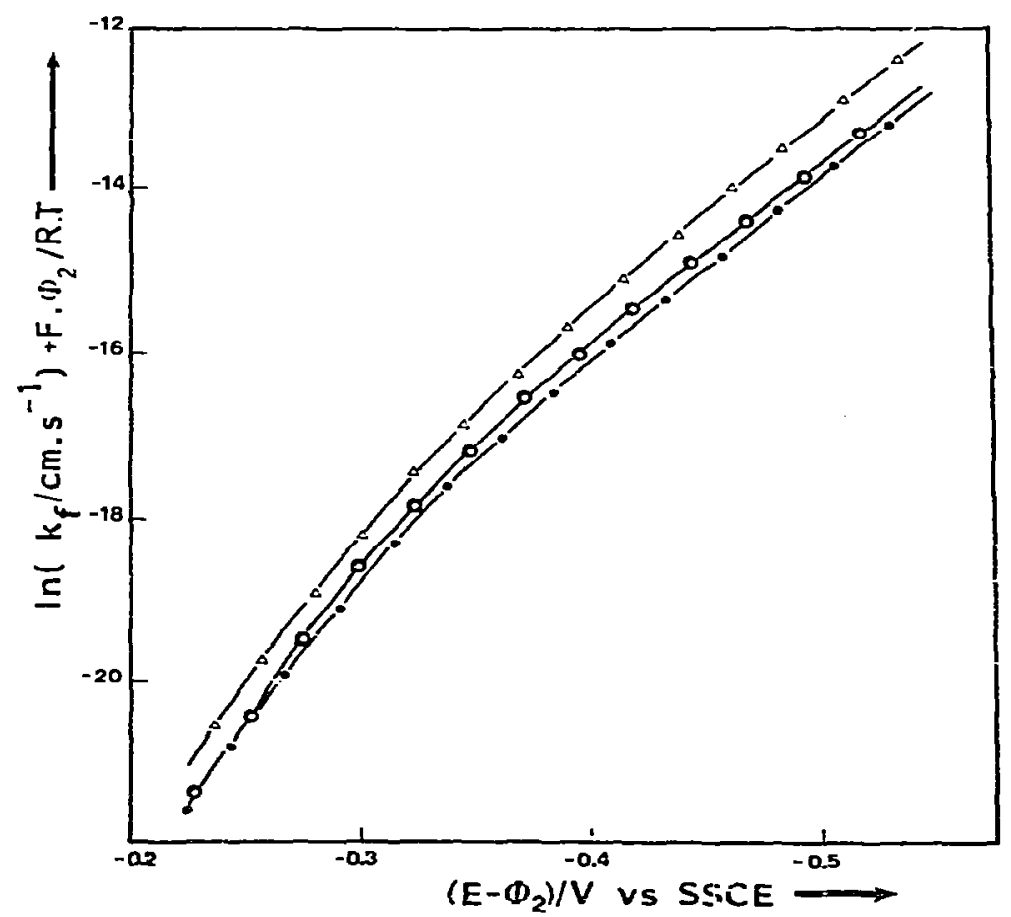

Fig. 8. Frumkin corrected plots, ln $k_{1}+(F / R T) \phi_{2}$ vs. $E-\phi_{2}$ for $1 M$ perchloric acid. ( $\left.\Delta\right)(110)$, (O) (100), (ब) (111) 
nature of the electrode metal and this has frequently been discussed in the literature $[9,11,13,14,34]$. It should be concluded that the well-known (empirical) correlation with the electronic work function $\left(\phi_{\mathrm{e}}\right)$ does not apply if faces of the same metal but with different crystallographic orientation are compared. For example, from Table $3 \mathrm{~A}$ we calculate the following exchange current densities $\left(i_{0}\right)$ :

$\begin{array}{llll}(110): & 3.7 \times 10^{-6} & \text { and } & 1.0 \times 10^{-7} \mathrm{~A} \mathrm{~cm}^{-2} \\ (100): & 3.4 \times 10^{-6} & \text { and } & 0.7 \times 10^{-7} \mathrm{~A} \mathrm{~cm}^{-2} \\ \text { (111): } & 1.75 \times 10^{-6} & \text { and } & 0.8 \times 10^{-7} \mathrm{~A} \mathrm{~cm}^{-2}\end{array}$

(the first column applying to the more negative part, and the second to the less negative part of the potential region studied). When the parallelism between the pzc and the electronic work function is accepted [37], the difference in electronic work function between $A u(110)$ and $A u(111)$ amounts to $\Delta \phi_{e} \approx 0.3 \mathrm{eV}$, so we find $\Delta \log$ $i_{0} / \Delta \phi_{e} \approx-1.1$, according to the first column. This is quite different from the value corresponding to exchange currents and work functions at different electrode metals, viz. $\Delta \log i_{0} / \Delta \phi_{e} \approx 7$, as has been calculated by Trasatti in his well-documented review [14]. Recently the weak variation of activity for hydrogen evolution with crystal face orientation was discussed and some possible explanations were given [15].

It has also been argued $[9,10]$ that the primary property for a correlation should be the Gibbs energy of adsorption of atomic hydrogen. However, it is not known whether this quantity could be inore or less dependent on the orientation of ihe lattice plane in the case of gold.

A correlation of the rate of the discharge reaction with the adsorption enthalpy will be irrelevant if the mechanism discussed in Section (IV.3.2) holds. In this case it is more feasible to think of an additional specific double-layer effect, e.g. inherent to a difference in the electric fie!d strength in the inner layer. In view of this it could be interesting to obtain more information about the degree of the hydration of $\mathrm{H}^{+}$and the way the hydration sheath is removed before or after electron transfer. Also, it should be investigated whether it is correct to assume the absence of any (perhaps orientation dependent) specific adsorption of the perchlorate ion. It is reasonable to believe the density of active sites to depend on crystallographic orientation, which could, via $k_{3}^{\prime}$ in eqn. (13), explain the variations of $L_{2}$ in Table 3.

With a view to the distinct difference of the rate of $R 1$ obtained at $4 \mathrm{~N}$ and $5 \mathrm{~N}$ quality of goid we should be aware that dependence of the kinetics on crystal face orientation could originate from orientation-dependent surface excesses of impurities. Experiments with intentionally contaminated electrode surfaces and intentionally contaminated bulk electrode material would be most elucidative on this point.

\section{ACKNOWLEDGEMENTS}

The authors wish to express their gratitude to Mr. A. van den Eeden and Mr. J.W. Deneer for valuable discussions and technical assistance, to the referee of this paper 
for his detailed comments and valuable suggestions an' to Dr. R. Parsons for his critical, but helpful assistance in preparing the final manuscript.

\section{REFERENCES}

1 D. Dickertmann, F.D. Koppitz and J.V!. Schultze, Electrochim. Acta, 21 (1976) 967.

2 A. Hamelin and A. Katayama, J. Electroanal. Chem., 117 (1981) 221.

3 A. Hamelin, T. Vitanov, E. Sevastyanov and A. Popov, J. Electroanal. Chem., 145 (1983) 225.

4 M.W. Breiter, J. Electroanal. Chem., 8 (1964) 230.

5 S. Gilnan, Electrochini. Acta, 9 (1964) 1025.

6 M. Sluyters-Rehbach and J.H. Sluyters in J.O'M Bockris and E Yeager (Eds.), Comprehensive Treatise on Electrochemistry, Vol. 9, Ch. 4, in press.

7 A.T. Kuhn and M. Byrne, Electrochim. Acta, 16 (1971) 391.

8 T. Sasaki and K. Matsuda, J. Res. Inst. Catal. Hokkaido Univ., 21 (1973) 157; 29 (1981) 113.

9 R. Parsons, Trans. Faraday Soc., 54 (1958) 1053.

10 H. Gerischer and W. Mehl, Z. Elektrochem., 59 (1959) 1049.

11 A.N. Frumkin in P. Delahay (Ed.), Advances in Elc--ochemistry and Electrochemical Engineering. Vol. 1, 1961, pp. 65-121; Vol. 3, 1963, pp. 287-391, Interscience, New York.

12 E. Gileadi and B.E. Conway in J.O'M Bockris (Ed.), Modern Aspects of Electrochemistry, Vol. 3. Butterworths, London, 1964, pp. 381-397.

13 A.J. Appleby, M. Chemla, H. Kita and G. Bronoël in A.J, Bard (Ed.). Encyclopedia of Electrochemistry of the Elements, Vol. IXa. Marcel Dekker. New York and Basel, 1982, pp. 413-556 (and references cited therein).

14 S. Trasatti, J. Electroanal. Chem., 39 (1972) 163.

15 S. Trasatti, Proc. Symp. "The Chemistry of Electrocatalysis", San Francisco, May 1983, The Electrochemical Society, Pennington, 1983, Ext. Abstr. 83-1, p. 1038.

16. L. Bicelli and M.R. Graziano, Rend. Ist. Lomb. Accad. Sci. Lett., A96 (1962) 98.

17 J.K. Mackenzie, A.I. Moore and J. Nicholas, J. Phys. Chem. Solids, 23 (1962) 185.

18 A. Hamelin and A. Lelan, C.R. Acad. Sci. Ser. B, 295 (1982) 161.

19 I. Clavilier, R. Faure, G. Guinet and R. Durand, J. Electroanal. Chem., 107 (1980) 205.

26. C.P.M. Bongenaar. M. Sluyters-Rehbach and J.H. Sluyters, J. Electroanal. Chem., 109 (1980) 23.

21 J. Clavilier, C.R. Acad. Sci. Ser. C, 263 (1966) 191.

22 A.N. Frumkin, P. Dolin and B. Ershler, Acta Physicochim. USSR, 13 (1940) 779.

23 B.E. -unway and M. Salomor, Electrochim. Acta, 9 (1964) 1599.

24 A.J. Bard and L.R. Faulkner, Electrochemical Methods, John Wiley and Sons, New York, $1980, p$. 166.

25 G.J. Brug, A.L.G. van den Eeder, M. Sluyters-Rehbach and J.H. Sluyters, J. Electroanal. Chem., 176 (1984) 275.

26 M. Sotto, J. Electroanal. Chem., 69 (1976) 229.

27 D. Dickertmann, J.W. Schultze and KJ. Vetter, J. Electroanal. Chem., 55 (1974) 429.

28 G.M. Schmid, Electrochim. Acta, 12 (1967) 449.

291 L.L. Krishtalik, J. Electrosnal. Chem., 100 (1980) 547.

30 L.J. Krisintalik, J. Electroanal. Chem., 130 (1981) 9.

31 R. Parsons, G. Picq and P. Vennereau, J. Electroanal. Chem., 146 (1983) 123.

32 A. Hamelin, G. Picq and P. Vennereau, J. Electroanal. Chem., 148 (1983) 61.

33 L.I. Krishtalik, Electrochim. Acta, 13 (1968) 1045.

34 L.1. Krishtalik in P. Delahay (Ed.), Advances in Electrochemistry and Electrochemical Engineering, Vol. 7, Interscience, New York, 1970, P. 283.

35 R.R. Dogonadze in N.S. Hush (Ed.), Reactions of Molecules at Electrodes, Wiley-Interscience, London, 1971, p. 135.

35 A. Hamelin and $Z$. Borkowska, unpublished results.

37 J. Lecoeur. J. Andro and R. Parsons, Surf. Sci., 114 (1982) 320. 